ЭКО. - 2018. - № 4

DOI: $10.30680 / \mathrm{ECO} 0131-7652-2018-4-116-132$

\section{Анализ факторов, определяющих различие в ожидаемой продолжительности жизни мужчин и женщин
в регионах России}

т.в. коссовА, кандидат экономических наук, Национальный исследовательский университет «Высшая школа экономики». E-mail: tkossova@hse.ru

E.в. КоссовА, кандидат физико-математических наук,

Национальный исследовательский университет «Высшая школа экономики» E-mail: e kossova@mail.ru

М.А. ШЕЛУНЦОВА, кандидат экономических наук,

Национальный исследовательский университет «Высшая школа экономики», Москва. E-mail: msheluntsova@hse.ru

Статья посвящена исследованию региональных различий в ожидаемой продолжительности жизни при рождении женщин и мужчин в России. В расчетах использовалась информация Федеральной службы государственной статистики за 1990-2014 гг. Анализ панельных данных показал наличие значимого положительного влияния потребления алкоголя на гендерное различие в ожидаемой продолжительности жизни. Результаты подтверждают важность поддержания ограничительных мер антиалкогольной политики

Ключевые слова: ожидаемая продолжительность жизни при рождении, смертность, потребление алкоголя, региональные различия, Россия

Ожидаемая продолжительность жизни при рождении - важный показатель, комплексно характеризующий уровень смертности в стране и активно используемый для анализа динамики продолжительности жизни, а также проведения межстрановых и межрегиональных сопоставлений. Задача увеличения продолжительности жизни населения является одной из ключевых для множества государственных программ, реализуемых в настоящее время в России. Данное обстоятельство обусловливает актуальность исследования факторов, которые оказывают существенное влияние на ожидаемую продолжительность жизни при рождении. Не менее важным представляется и объяснение гендерных различий в этой сфере. Несмотря на то, что разница продолжительности жизни мужчин

${ }^{1}$ Исследование осуществлено в рамках Программы фундаментальных исследований НИУ ВШЭ в 2017 г. и женщин наблюдается повсеместно, обращает на себя внимание относительно большое значение данного показателя для России и других постсоветских стран. По данным Всемирной организации здравоохранения за 2013 г., оно составляет 10-12 лет, причем для России также характерны существенные межрегиональные различия, составлявшие с 1998 г. по 2014 г. в среднем от восьми до 16 лет для разных регионов, что превышает аналогичные значения для развитых стран.

Целью настоящего исследования является анализ факторов, оказывающих значимое влияние на величину разницы в ожидаемой продолжительности мужчин и женщин в регионах России. Информация Федеральной службы государственной статистики позволяет рассмотреть влияние макроэкономических детерминант в разрезе регионов и сделать выводы относительно возможностей государственной политики, направленной на снижение смертности и увеличение ожидаемой продолжительности жизни населения страны.

\section{Международные сопоставления}

Превышение ожидаемой продолжительности жизни при рождении для женщин над соответствующим показателем для мужчин является общепризнанным и находит множество эмпирических подтверждений [Liu et al., 2013]. Величина этой разницы варьируется по странам и изменяется для одной и той же страны с течением времени. Международные сопоставления позволяют установить величину гендерного различия в ожидаемой продолжительности жизни, характерную для экономически развитых и развивающихся стран, определить место России в мире по данному показателю и сравнить результаты с фактическими значениями, наблюдаемыми в регионах РФ.

Для этого мы используем данные Всемирной организации здравоохранения за 2013 г. $^{2}$ Проведем кластерный анализ 193 стран, выбрав в качестве показателей ожидаемую продолжительность жизни при рождении мужчин и женщин. Задавая число кластеров, равное трем, мы получаем группы стран с высокой, средней и низкой продолжительностью жизни. В качестве

World Health Organization 2016. Life expectancy. Data by country. URL: http://apps. who.int $/$ gho/data/node.main.688?lang=en 
метода кластеризации используем метод k-медиан с обычным евклидовым расстоянием.

В группу с высокой продолжительностью жизни вошли 44 страны (государства Западной Европы, а также США, Канада, Австралия, Новая Зеландия, Япония, Южнокорейская Республика, Сингапур, Израиль, Чили, некоторые страны Азии, Южной Америки и Карибского бассейна).

В группу со средней продолжительностью жизни вошло 91 государство, в том числе Россия и бывшие постсоветские страны (за исключением Туркменистана), государства Восточной Европы, Китай и большинство стран Азии, страны Центральной и Южной Америки, Северной Африки и Намибия, а также страны Океании. В группу с относительно низкой ожидаемой продолжительностью жизни вошли 58 стран, большая часть из которых расположены в Африке, а также Индия, Пакистан, Туркменистан и Монголия.

Рассмотрим, какая гендерная разница в ожидаемой продолжительности жизни характерна для этих групп стран (табл. 1).

Таблица 1. Описательные статистики для разных групп стран, лет

\begin{tabular}{|c|c|c|c|c|}
\hline Переменная & Среднее & $\begin{array}{l}\text { Стандартное } \\
\text { отклонение }\end{array}$ & Минимум & Максимум \\
\hline \multicolumn{5}{|c|}{ Для группы стран с высокой ожидаемой продолжительностью жизни } \\
\hline $\begin{array}{l}\text { Ожидаемая продолжительность жизни при } \\
\text { рождении: }\end{array}$ & & & & \\
\hline у мужчин & 78,6 & 1,87 & 75 & 83 \\
\hline у женщин & 83,2 & 1,87 & 79 & 87 \\
\hline $\begin{array}{l}\text { Разница в ожидаемой продолжительности } \\
\text { жизни при рождении у мужчин и женщин }\end{array}$ & 4,61 & 1,64 & 1 & 8 \\
\hline \multicolumn{5}{|c|}{ Для группы стран со средней ожидаемой продолжительностью жизни } \\
\hline $\begin{array}{l}\text { Ожидаемая продолжительность жизни при } \\
\text { рождении: }\end{array}$ & & & & \\
\hline у мужчин & 70,6 & 3,04 & 63 & 76 \\
\hline у женщин & 76,4 & 2,99 & 69 & 82 \\
\hline $\begin{array}{l}\text { Разница в ожидаемой продолжительности } \\
\text { жизни при рождении у мужчин и женщин }\end{array}$ & 5,76 & 2,36 & 1 & 12 \\
\hline \multicolumn{5}{|c|}{ Для группы стран с низкой ожидаемой продолжительностью жизни } \\
\hline $\begin{array}{l}\text { Ожидаемая продолжительность жизни при } \\
\text { рождении: } \\
\text { у мужчин }\end{array}$ & 58,5 & 4,8 & 46 & 65 \\
\hline у женщин & 61,4 & 5,5 & 46 & 70 \\
\hline $\begin{array}{l}\text { Разница в ожидаемой продолжительности } \\
\text { жизни при рождении у мужчин и женщин }\end{array}$ & 2,98 & 1,6 & 0 & 8 \\
\hline
\end{tabular}

Значения показателей ожидаемой продолжительности жизни для мужчин и женщин в группе стран со средней продолжительностью жизни приблизительно на восемь лет ниже, чем в странах первой группы. При этом гендерная разница в продолжительности жизни увеличивается в среднем от 4,6 лет до 5,75 лет при переходе от первой группы стран ко второй. Следует отметить, что наибольшая разница в ожидаемой продолжительности жизни мужчин и женщин во второй группе стран характерна для постсоветского пространства, причем максимальные значения наблюдаются в России и Беларуси (12 лет).

Ожидаемая продолжительность жизни как мужчин, так и женщин в странах третьей группы на 20 лет меньше, чем в странах первой группы. Интересно отметить, что здесь наблюдается наименьшая разница в ожидаемой продолжительности жизни мужчин и женщин - в среднем около трех лет.

Поскольку в группе стран с высокой ожидаемой продолжительностью жизни максимальная разница в значении показателя для мужчин и женщин составила восемь лет, в дальнейшем анализе региональных различий в России мы будем использовать это значение в качестве ориентира.

Таким образом, наименьшая разница в ожидаемой продолжительности жизни мужчин и женщин имеет место в странах с наименьшей продолжительностью жизни, эти же страны являются наиболее бедными. При повышении продолжительности жизни данная разница увеличивается и вновь сокращается при достижении высоких значений рассматриваемого показателя, которые наблюдаются в экономически развитых странах. Указанная закономерность может объясняться неравномерностью увеличения продолжительности жизни для разных групп населения.

В целом причины существования гендерной разницы в ожидаемой продолжительности жизни могут крыться в биологических различиях полов [Van Oyen et al., 2010] и в генетических факторах [Triokhin et al., 2004]. У мужчин наблюдается большая склонность к нездоровому образу жизни [Van Oyen et al., 2010; Jusrut and Kalipeni, 2012], что может привести к преждевременному разрушению здоровья и смерти. Женщины чаще мужчин прибегают к профилактике медицинских заболеваний, имеют лучшие социальные связи, что способствует увеличению продолжительности жизни [Jusrut and Kalipeni, 2012]. Конти и др. 
в исследовании для Италии пришли к выводу, что сокращение гендерного различия в ожидаемой продолжительности жизни может быть обусловлено появившейся склонностью вести нездоровый образ жизни у женщин при обратной тенденции у молодых мужчин [Conti et al., 2003]. Более высокая смертность мужского населения может быть связана с тем, что мужчины чаще злоупотребляют алкоголем и курением [Van Oyen et al., 2010].

Сокращение или же увеличение разницы в ожидаемой продолжительности жизни мужчин и женщин может объясняться вкладом различных причин смерти. Так, для Республики Корея причины смертности, связанные с курением, существенно влияют на увеличение гендерного разрыва в ожидаемой продолжительности жизни, а смертность в результате дорожно-транспортных происшествий, наоборот, сокращает этот разрыв [Yang et al., 2012]. Отметим, что из всей совокупности причин выделяются также социально-экономические факторы, а именно, уровень доходов, показатели экономического неравенства, занятости и безработицы [Clark and Peck, 2012].

\section{Различия в регионах России}

На рисунке 1 представлен график ожидаемой продолжительности жизни мужчин и женщин по России в целом за 1990-2015 гг. Как мы видим, за 1990-1994 гг. средняя продолжительность жизни населения России резко сокращалась, далее к 1998 г. половина потерь была компенсирована, но затем негативная тенденция продолжилась до 2003 г., после чего начался период увеличения значений показателя. Продолжительность жизни у женщин достигла значений 1990 г. только в 2008 г., а у мужчин - к 2011 г. В 2015 г. продолжительность жизни мужчин и женщин превысила соответствующие значения показателя 1990 г. на 2,22 и 2,41 года соответственно.

Указанная динамика продолжительности жизни объясняется изменениями экономической и политической ситуации в стране в рассматриваемый временной период. Как видно из графика, показатели средней продолжительности жизни мужчин реагировали на происходящие изменения сильнее, чем у женщин, что проявлялось в изменении величины разницы между ними. В 1990 г. гендерная разница в продолжительности жизни составляла 10,6 лет, к 1994 г. она увеличилась до 13,7 лет, после 2005 г. она начала сокращаться и в 2015 г. составила 10,79 года.

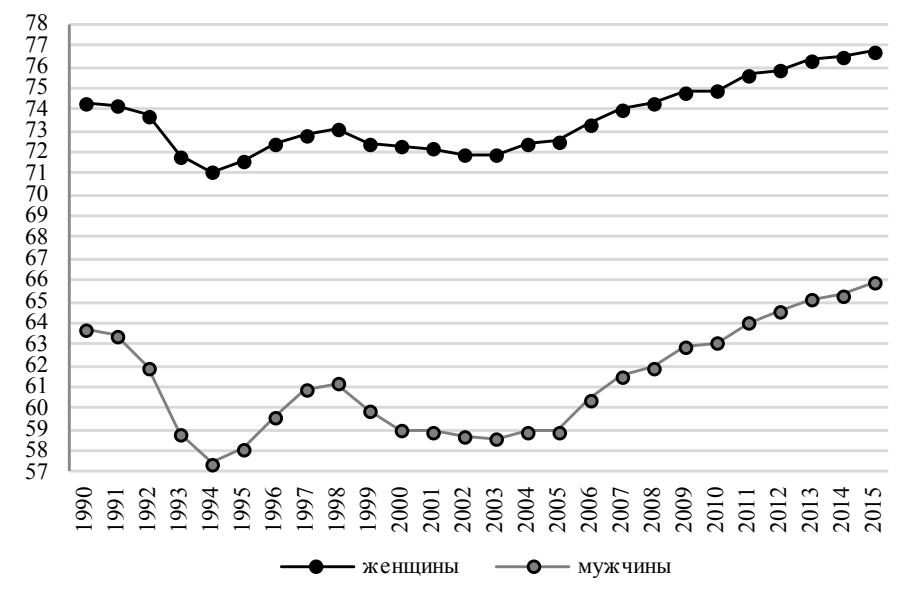

Источник: Росстат.

Рис. 1. Динамика показателя «ожидаемая продолжительность жизни при рождении» в России в 1990-2015 гг.

Похожая тенденция наблюдается и на региональном уровне. При этом разброс в значениях разницы продолжительности жизни по регионам весьма существен. Наименьшие гендерные различия по данному показателю в 2015 г. наблюдаются в северокавказских республиках - Чечне, Ингушетии и Дагестане (около шести лет), а также в Москве $(7,40)$ и Санкт Петербурге $(8,55)$. Максимальные различия (около 13 лет) характерны для Орловской области и Республики Марий Эл.

Проблема существования большого разрыва в ожидаемой продолжительности жизни мужчин и женщин в России широко обсуждается в российской научной литературе [Андреев, 2003; Харченко и др., 2003; Кваша и Харькова, 2011; Школьников и др., 2014; Аганбегян, 2015]. Среди факторов выделяются структурные изменения, происходящие в российском обществе [Pietilä and Rytkönen, 2008], стрессы и нездоровый образ жизни [Cockerham, 2012].

С целью проверки соответствия динамики гендерной разницы продолжительности жизни в российских регионах выявленной 
общемировой тенденции мы провели для них кластерный анализ, аналогичный тому, что был описан выше для зарубежных стран. Для проведения расчетов использовались данные Росстата за 1990-2014 гг. На рисунке 2 представлены значения средней ожидаемой продолжительности жизни мужчин и женщин для получившихся кластеров.

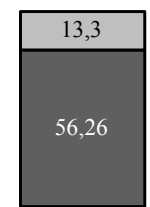

Кластер 1

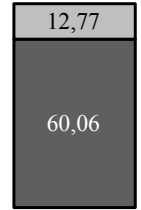

Кластер 2

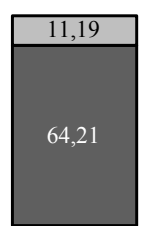

Кластер 3
口Разница в продолжительности жизни женщин и мужчин

口Продолжительность жизни мужчин

Рис. 2. Средняя ожидаемая продолжительность жизни для трех кластеров, лет

В группе регионов с относительно низкой продолжительностью жизни (538 наблюдений) значение данного показателя для мужчин чуть превысило 56 лет, для женщин - 69,5 лет, а гендерное различие в ожидаемой продолжительности жизни 13,3 года. Для группы регионов, где среднее значение ожидаемой продолжительности жизни мужчин составляет 60 лет, а женщин - чуть менее 73 лет, наблюдается чуть меньше гендерное различие (12,8 лет). В группе с относительно высокой ожидаемой продолжительностью жизни (64 года для мужчин и 75,4 - для женщин) гендерное различие составило в среднем 11,2 года. Таким образом, для регионов с более высокими показателями продолжительности жизни в среднем наблюдаем и меньшее различие в продолжительности жизни мужчин и женщин, что соответствует отмеченной общемировой тенденции.

Кластерный анализ ожидаемой продолжительности жизни мужчин и женщин в разных странах выявил, что наиболее высокие значения данного показателя наблюдаются в экономически развитых странах. Чтобы проверить, имеет ли место проявившаяся на межстрановом уровне тенденция в регионах России, проведем кластеризацию российских регионов по показателям, характеризующим экономическое благополучие населения и его склонность к нездоровому образу жизни. Статистическими показателями здесь выступили среднедушевые денежные доходы, уровень безработицы и потребление алкоголя. Необходимость учета последнего фактора обусловлена наличием положительной связи между уровнем экономического благополучия региона и потреблением алкоголя, с одной стороны, а также потреблением алкоголя и средней продолжительностью жизни - с другой [Kossova et al., 2014].

В настоящей работе объем потребления алкоголя в регионе определяется как зарегистрированный объем продаж алкогольных напитков в пересчете на литры абсолютного алкоголя на человека в год. Выбор такого показателя является вынужденным ввиду отсутствия статистики по потреблению алкоголя, в том числе незарегистрированному. Анализ проводился по показателям 77 регионов за 1998-2014 гг. (без Ингушетии, Дагестана и Чечни). В результате регионы разделились на три группы: регионы с низким доходом, высоким уровнем безработицы и низким потреблением алкоголя (кластер 1), регионы со средним доходом, средним уровнем безработицы и средним потреблением алкоголя (кластер 2), регионы с высоким доходом, низким уровнем безработицы и высоким потреблением алкоголя (кластер 3) (рис. 3).

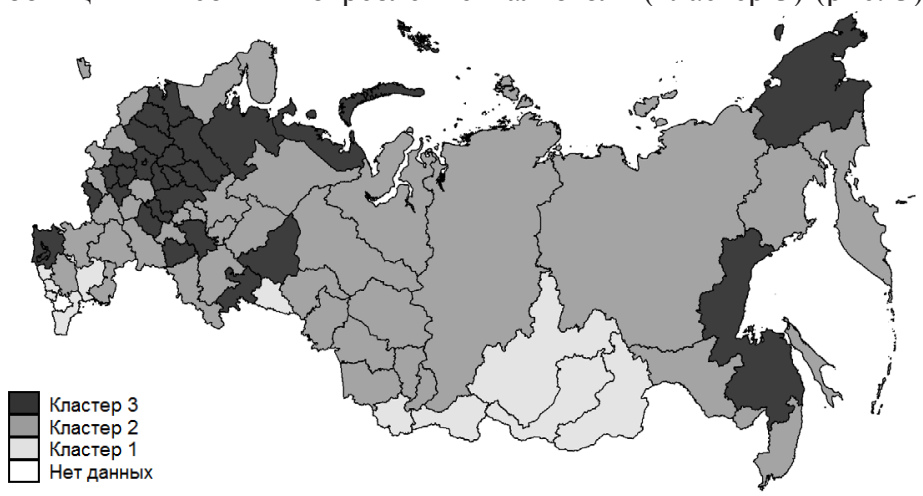

Рис. 3. Карта разбиения регионов на три кластера по среднедушевым денежным доходам, уровню безработицы и потреблению алкоголя

Анализ показывает, что для регионов с более высоким уровнем доходов и меньшей безработицей в среднем характерны большее потребление алкоголя, более высокая смертность от внешних причин, а также большая разница в ожидаемой продолжительности жизни мужчин и женщин. Следует отметить, что в экономически более благополучных регионах 
продолжительность жизни женщин выше, чем в менее благополучных, но продолжительность жизни мужчин практически не различается. Одним из возможных объяснений является то, что благосостояние региона, с одной стороны, положительно влияет на среднюю продолжительность жизни его жителей, a c другой - с повышением дохода увеличивается потребление алкоголя, в результате чего растет смертность от внешних и прочих причин, и, как следствие, снижается продолжительность жизни мужчин. В результате в третьем кластере наблюдается наибольшее различие в ожидаемой продолжительности жизни.

Для проверки гипотезы о наличии взаимосвязи гендерного различия в продолжительности жизни с характеристиками нездорового поведения мужчин, а именно, потреблением алкоголя, перейдем к эконометрическому анализу.

\section{Эконометрический анализ}

Для оценки влияния макроэкономических факторов на различие в продолжительности жизни мужчин и женщин в регионах России мы используем статистическую информацию Федеральной службы государственной статистики по 77 регионам за 1998-2014 гг

В качестве объясняющих переменных мы рассматриваем среднедушевые денежные доходы населения (переменная income), уровень безработицы (переменная unempl) и коэффициент Джини (переменная gini). Поскольку исследуемое различие может быть связано с нездоровым образом жизни, мы учитываем смертность от внешних причин (переменная death_ext) и потребления алкоголя (переменная alc). Включение в уравнение и смертности, и потребления алкоголя позволяет выделить влияние потребления алкоголя на другие составляющие продолжительности жизни. Кроме того, существенный вклад в сокращение продолжительности жизни, предположительно, вносит курение. Поскольку в нашем распоряжении нет данных о проценте курильщиков в разрезе по регионам России, в качестве прокси переменной используется смертность от болезней органов дыхания (переменная death_breath). Мы учитываем тот факт, что коэффициенты при переменных могут меняться от кластера к кластеру, поэтому вводим дамми переменные $\mathrm{C}_{\text {( }}(\mathrm{k}=1,2,3)$, принимающие значение, равное единице, если регион входит в кластер k, и ноль - во всех остальных случаях.

В качестве зависимой переменной используется логарифм отношения ожидаемой продолжительности жизни женщин $\left(\mathrm{LE}_{\text {women }}\right)$ к продолжительности жизни мужчин $\left(\mathrm{LE}_{\text {men }}\right)$ Все объясняющие переменные также взяты в логарифмах. При данной спецификации коэффициенты модели интерпретируются как процентное изменение рассматриваемого отношения при изменении на один процент соответствующей независимой переменной. Мы оцениваем следующую модель с фиксированными эффектами: $\ln \left(\right.$ ratio $\left._{i t}\right)=\alpha+\beta_{1 c} \ln \left(\right.$ alc $\left._{i t}\right)+\beta_{2 c} \ln \left(\right.$ death_ext $\left._{i t}\right)+\beta_{3 c} \ln \left(\right.$ death_breath $\left.{ }_{i t}\right)+$ $+\beta_{4 c} \ln \left(\right.$ income $\left._{i t}\right)+\beta_{5 c} \ln \left(\right.$ unempl $\left._{i t}\right)+\beta_{6 c} \ln \left(\right.$ gini $\left._{i t}\right)+\alpha_{i}+\varepsilon_{i t}$,

$$
\text { где } \beta_{j c}=\left\{\begin{array}{c}
\beta_{j}, \quad \text { для кластера } c=1 \\
\beta_{i}+\Delta \beta_{i c}, \quad \text { для кластера } c=2,3 \text {; }
\end{array}\right.
$$

$\mathrm{i}=1, . ., 77 \mathrm{t}=1998, . ., 2014, \alpha_{i}-$ фиксированный эффект региона i, $\varepsilon_{i t}$ - случайные составляющие, подчиняющиеся стандартным предположениям о независимости и нормальном распределении.

Таким образом, для региона из первого кластера коэффициент при переменной ј равен $\beta_{j}$, а для регионов из второго и третьего кластеров $-\beta_{j}+\Delta \beta_{j c} \quad(\mathrm{c}=2,3)$.

Результаты оценивания полной модели приведены в Приложении (табл. 1П), сокращенной модели - в табл. 11П (после проверки гипотезы о наличии несущественных переменных - в табл. 111П).

\section{Таблица 2. Результаты оценивания модели}

\begin{tabular}{|c|c|c|}
\hline Коэффициент & Переменные & Ln(ratio) \\
\hline$\beta_{1}$ & $\operatorname{Ln}(\mathrm{alc})$ & $0,0043^{\star \star \star}(0,001)$ \\
\hline$\Delta \beta_{13}$ & $\operatorname{Ln}(\mathrm{alc})^{\star} \mathrm{C}_{3}$ & $0,0055^{\star \star}(0,002)$ \\
\hline$\beta_{2}$ & Ln(death_ext) & $0,075^{\star \star \star}(0,002)$ \\
\hline$\beta_{3}$ & Ln(breath) & $0,0062^{\star \star \star}(0,001)$ \\
\hline$\beta_{4}$ & Ln(income) & $-0,0034^{\star \star}(0,001)$ \\
\hline$\Delta \beta_{43}$ & Ln(income) ${ }^{\star} \mathrm{C}_{3}$ & $-0,0074^{\star \star \star}(0,002)$ \\
\hline$\beta_{5}$ & Ln(unempl) & $-0,0068^{\star \star \star}(0,001)$ \\
\hline \multirow[t]{5}{*}{$\Delta \beta_{63}$} & $\operatorname{Ln}\left(\right.$ gini) ${ }^{*} \mathrm{C}_{3}$ & $0,013^{\star \star \star}(0,004)$ \\
\hline & Constant & $-0,219^{\star \star \star}(0,009)$ \\
\hline & Observations & 1303 \\
\hline & R-squared & 0,84 \\
\hline & Number of reg & 77 \\
\hline \multicolumn{3}{|c|}{ Standard errors in parentheses ${ }^{* \star \star} p<0,01,{ }^{* \star} p<0,05,{ }^{*} p<0,1$} \\
\hline
\end{tabular}

Как видно из таблицы 2, в регионах с более высоким потреблением алкоголя наблюдается и большая разница в продолжительности жизни мужчин и женщин, причем этот эффект оказывается сильнее в третьем кластере, который охватывает наиболее благополучные с экономической точки зрения регионы. Здесь наиболее сильно проявляется отрицательная зависимость различий в продолжительности жизни от уровня среднедушевых денежных доходов населения и положительная зависимость от объема потребления алкоголя: соответствующие коэффициенты в два раза выше, чем в других кластерах. 
Таким образом, проблема негативного влияния потребления алкоголя на продолжительность жизни проявляется наиболее остро там, где доходы населения относительно высоки, и где сравнительно более высокий уровень благосостояния позволяет покупать и потреблять больший объем алкогольных напитков. Потребление алкоголя сокращает, в первую очередь, ожидаемую продолжительность жизни мужчин, поскольку они в большей степени проявляют склонность к нездоровому образу жизни и вредным привычкам. Отрицательная связь гендерного различия продолжительности жизни и уровня среднедушевых доходов подтверждает то, что для регионов России верна тенденция, проявившаяся на международном уровне, а именно, сокращение гендерного различия с ростом экономического благополучия.

Коэффициент Джини оказался значимым только в третьем кластере. Чем выше данный коэффициент, тем более существенны гендерные различия в ожидаемой продолжительности жизни. Неравенство населения по доходам создает напряженную социальную обстановку, что при прочих равных условиях подталкивает к большему употреблению алкогольных напитков, особенно мужской части населения. Вывод о направлении влияния коэффициента Джини на величину гендерных различий согласуется с межстрановым анализом Кларка и Пекка (2012).

Еще одним показателем, характеризующим экономическое благополучие региона, выступает уровень безработицы. Данный фактор оказался значимым во всех трех кластерах. Чем выше уровень безработицы, тем меньше и потребление алкоголя в регионе, и гендерные различия в ожидаемой продолжительности жизни. Скорее всего, меньший объем потребления алкоголя оказывает положительное влияние на ожидаемую продолжительность жизни мужчин, тем самым сокращая гендерный разрыв в ожидаемой продолжительности жизни.

Во всех трех кластерах наиболее весомым фактором, объясняющим разницу в ожидаемой продолжительности жизни мужчин и женщин, является смертность от внешних причин. Травмы, несчастные случаи, дорожно-транспортные происшествия и другие факторы, включаемые в данный коэффициент, сокращают в первую очередь жизнь мужчин. Смертность от болезней органов дыхания также является значимым фактором. Положительная взаимосвязь данного показателя с гендерным различием в продолжительности жизни, по-видимому, объясняется тем, что мужчины умирают от данного вида болезней чаще, чем женщины. Статистическая значимость данных коэффициентов смертности от внешних причин и болезней органов дыхания еще раз подтверждает негативное влияние склонности к нездоровому образу жизни на гендерные различия в ожидаемой продолжительности жизни и указывает на мужское население как на наиболее уязвимую категорию.

\section{Заключение}

Исследование межрегиональных различий, подкрепленное межстрановыми сравнениями, показало, что наименьшие гендерные различия в ожидаемой продолжительности жизни при рождении наблюдаются в тех регионах России, где экономическая ситуация является либо наиболее благополучной, либо наоборот - наименее благополучной. В результате кластерного анализа выявлено, что регионы с более высокими среднедушевыми денежными доходами населения демонстрируют также и более высокие объемы потребления алкогольных напитков. Из этого следует, что для изучения детерминант гендерной разницы в ожидаемой продолжительности жизни недостаточно традиционных макроэкономических показателей. Необходимо также учитывать фактор следования здоровому образу жизни.

Данный вывод был подкреплен результатами эконометрического анализа, который показал наличие значимого влияния потребления алкоголя на различие в ожидаемой продолжительности жизни женщин и мужчин в регионе. Чем выше объем потребления алкогольных напитков, тем больше данное различие. В основном это объясняется сокращением ожидаемой продолжительности жизни мужчин, демонстрирующих большую, чем женщины, склонность к нездоровому поведению. Существенными факторами также являются макроэкономические показатели дохода, уровня безработицы, неравенства доходов и коэффициенты смертности. Таким образом, сокращение разрыва в ожидаемой продолжительности жизни женщин и мужчин в России связано не только с улучшением общей экономической ситуации в регионах, но также и с факторами следования здоровому образу жизни главным образом, сокращением объемов потребления алкоголя. 
Данный факт необходимо учитывать при выборе мер политики, направленной на увеличение продолжительности жизни населения в стране. Поскольку существует прямое влияние потребления алкоголя на различие в ожидаемой продолжительности жизни, можно говорить о недопустимости ослабления принятых на сегодняшний день антиалкогольных мер в стране, например, понижение установленной минимальной цены на водку, снижение акцизов на крепкий алкоголь, снятие ограничений на торговлю алкоголем в Интернете и временных ограничений на продажу алкоголя как на федеральном, так и региональных уровнях. Иначе это приведет к сокращению ожидаемой продолжительности жизни, в первую очередь мужчин. Ввиду того, что улучшение макроэкономических показателей в регионах идет параллельно с увеличением объемов потребляемых алкогольных напитков, необходимо даже в условиях экономического роста поддерживать запретительные и ограничительные меры антиалкогольной политики.

Приложение. Описательные статистики по кластерам: 77 peгионов, 1998-2014 гг.

Кластер 1 состоит из 11 регионов: Забайкальский кр., Иркутская обл, Курганская обл., Респ. Алтай, Респ. Бурятия, Респ. Калмыкия, Респ. Тыва, Респ. Адыгея, Кабардино-Балкарская Респ., Карачаево-Черкесская Респ., Северная Осетия - Алания. Ингушетия, Дагестан и Чечня были исключены из-за большого числа пропусков в данных.

Таблица / п.

\begin{tabular}{|l|c|c|c|c|c|}
\hline \multicolumn{1}{|c|}{ Переменная } & $\begin{array}{c}\text { Количество } \\
\text { наблюдений }\end{array}$ & Среднее & $\begin{array}{c}\text { Стандартное } \\
\text { отклонение }\end{array}$ & Минимум & Максимум \\
\hline $\begin{array}{l}\text { Потребление абсолютного } \\
\text { алкоголя (начеловекавгод), л }\end{array}$ & 187 & 6,38 & 3,36 & 1,1 & 27,1 \\
\hline $\begin{array}{l}\text { Среднедушевые денежные } \\
\text { доходы, руб./мес. }\end{array}$ & 187 & 7520,84 & 6004,4 & 455 & 22326 \\
\hline Уровень безработицы,\% & 187 & 14,24 & 5,18 & 7 & 32 \\
\hline Коэффициент Джини & 187 & 0,37 & 0,027 & 0,31 & 0,426 \\
\hline Коэффициент фертильности & 187 & 1,77 & 0,43 & 1,19 & 3,49 \\
\hline $\begin{array}{l}\text { Число умерших от внешних } \\
\text { причин смерти на 100000 } \\
\text { чел. населения }\end{array}$ & 187 & 1289,3 & 224,3 & 880,8 & 1804,9 \\
\hline $\begin{array}{l}\text { Ожид. продолжительность } \\
\text { жизни при рождении, лет: } \\
\text { женщин }\end{array}$ & 187 & 72,4 & 4,06 & 60,2 & 79,06 \\
\hline мужчин & 187 & 60,35 & 4,74 & 48,2 & 69,36 \\
\hline
\end{tabular}

\begin{tabular}{|l|c|c|c|c|c|}
\hline \multicolumn{1}{|c|}{ Переменная } & $\begin{array}{c}\text { Количество } \\
\text { наблюдений }\end{array}$ & Среднее & $\begin{array}{l}\text { Стандартное } \\
\text { отклонение }\end{array}$ & Минимум & Максимум \\
\hline $\begin{array}{l}\text { Разница в ожид. продолжи- } \\
\text { тельности жизни женщин } \\
\text { и мужчин, лет }\end{array}$ & 187 & 12,04 & 1,32 & 9,05 & 15,3 \\
\hline
\end{tabular}

Кластер 2 состоит из 39 регионов: Алтайский кр., Амурская обл., Астраханская обл., Брянская обл., Волгоградская обл., Воронежская обл., Еврейская автономная обл., Калининградская обл., Камчатский кр., Кемеровская обл., Кировская обл., Красноярский кр., Курская обл., Магаданская обл., Мурманская обл., Новосибирская обл., Омская обл., Оренбургская обл., Пермский кр., Приморский кр., Псковская обл., Респ. Башкортостан, Респ. Карелия, Респ. Коми, Респ. Марий Эл, Респ. Саха (Якутия), Респ. Хакасия, Ростовская обл., Рязанская обл., Саратовская обл., Сахалинская обл., Смоленская обл., Ставропольский кр., Тамбовская обл., Томская обл., Тюменская обл., Удмуртская Респ., Ульяновская обл., Чувашская Респ.

Таблица // п.

\begin{tabular}{|l|c|c|c|c|c|}
\hline \multicolumn{1}{|c|}{ Переменная } & $\begin{array}{c}\text { Количество } \\
\text { наблюдений }\end{array}$ & Среднее & $\begin{array}{c}\text { Стандартное } \\
\text { отклонение }\end{array}$ & Минимум & Максимум \\
\hline $\begin{array}{l}\text { Потребление абсолютно- } \\
\text { го алкоголя (на человека } \\
\text { в год), л }\end{array}$ & 663 & 8,36 & 2,28 & 3 & 16,1 \\
\hline $\begin{array}{l}\text { Среднедушевые денежные } \\
\text { доходы, руб./мес. }\end{array}$ & 663 & 10409,36 & 8670,2 & 422 & 45846 \\
\hline Уровень безработицы,\% & 663 & 8,93 & 3,03 & 2,9 & 23,9 \\
\hline Коэффициент Джини & 663 & 0,37 & 0,03 & 0,255 & 0,465 \\
\hline Коэффициентфертильности & 663 & 1,44 & 0,24 & 0,99 & 2,25 \\
\hline $\begin{array}{l}\text { Число умерших от внешних } \\
\text { причин смерти на 1000о0 } \\
\text { чел. населения }\end{array}$ & 663 & 1490,4 & 268,1 & 817,9 & 2485 \\
\hline $\begin{array}{l}\text { Ожид. продолжительность } \\
\text { жизни при рождении, лет: } \\
\text { женщин }\end{array}$ & 661 & 72,8 & 2,23 & 65,8 & 77,4 \\
\hline мужчин & 661 & 60,2 & 2,82 & 53,7 & 67,9 \\
\hline $\begin{array}{l}\text { Разница в ожид. продолжи- } \\
\text { тельности жизни женщин } \\
\text { и мужчин, лет }\end{array}$ & 661 & 12,66 & 1,1 & 9,36 & 16,1 \\
\hline
\end{tabular}

"По некоторым показателям имеется на два наблюдения меньше из-за отсутствия данных за 2011 и 2012 гг. по Саратовской области.

Кластер 3 состоит из 27 регионов: Архангельская обл., Белгородская обл., Владимирская обл., Вологодская обл., Ивановская обл., Калужская обл., Костромская обл., Краснодарский кр., Ленинградская обл., Липецкая обл., Московская обл., Нижегородская обл., Новгородская обл., Орловская обл., Пензенская обл., Респ. Мордовия, Респ. Татарстан, Самарская обл., Свердловская обл., Тверская обл., Тульская обл., Хабаровский кр., Челябинская обл., Чукотский округ, Ярославская обл., Москва, Санкт-Петербург. 
Таблица III п.

\begin{tabular}{|l|c|c|c|c|c|}
\hline \multicolumn{1}{|c|}{ Переменная } & $\begin{array}{c}\text { Количество } \\
\text { наблюдений }\end{array}$ & Среднее & $\begin{array}{c}\text { Стандарт- } \\
\text { ное откло- } \\
\text { нение }\end{array}$ & Минимум & Максимум \\
\hline $\begin{array}{l}\text { Потребление абсолютного } \\
\text { алкоголя (начеловекавгод), л }\end{array}$ & 459 & 8,79 & 2,48 & 2,1 & 19,1 \\
\hline $\begin{array}{l}\text { Среднедушевые денежные } \\
\text { доходы, руб./мес. }\end{array}$ & 459 & 11435,98 & 10396,47 & 512 & 57310 \\
\hline Уровень безработицы,\% & 459 & 6,47 & 2,96 & 0,8 & 18,6 \\
\hline Коэффициент Джини & 459 & 0,37 & 0,05 & 0,24 & 0,595 \\
\hline Коэффициент фертильности & 459 & 1,35 & 0,23 & 0,86 & 2,04 \\
\hline $\begin{array}{l}\text { Число умерших от внешних } \\
\text { причин смерти на 100000 } \\
\text { чел. населения }\end{array}$ & 459 & 1636,5 & 278,1 & 824,1 & 2411,5 \\
\hline $\begin{array}{l}\text { Ожид. продолжительность } \\
\text { жизни при рождении, лет: } \\
\text { женщин }\end{array}$ & 459 & 73,38 & 2,69 & 61,2 & 80,38 \\
\hline мужчин & 459 & 60,53 & 3,53 & 51 & 72,77 \\
\hline $\begin{array}{l}\text { Разница в ожид. продол- } \\
\text { жительности жизни женщин } \\
\text { и мужчин, лет }\end{array}$ & 459 & 12,85 & 1,58 & 7,61 & 15,9 \\
\hline
\end{tabular}

\section{Литература}

Аганбегян А.Г. Повышение крайне низкой продолжительности жизни населения России - важнейшая неотложная задача // Экономические стратегии. 2015. T. 17. № 5-6(130-131). С. 60-79.

Андреев E.M. Почему в России так велик разрыв в продолжительности жизни мужчин и женщин (Опубликовано в журнале «Вопросы статистики». 2001. № 7 под названием «Смертность мужчин в России») // Демоскоп Weekly. 2003. № 131-132. URL: http://demoscope.ru/weekly/2003/0131/analit05.php

Кваша Е.А., Харькова Т.Л. Ожидаемая продолжительность жизни взрослого населения в регионах России в последнее десятилетие // Вопросы статистики. 2011. № 8. C. 26-41.

Харченко В.И., Михайлова Р.Ю., Онищенко П.И. Показатели продолжительности жизни населения России в сравнении с другими странами // Проблемы прогнозирования. 2003. № 6. С. 119-127.

Школьников В.М., Андреев Е.М., Макки М., Леон Д.А. Рост продолжительности жизни в России 2000-х годов // Демографическое обозрение. 2014. Т. 1. № 2(2). C. 5-37.

Clark R., Peck M.B. Examining the Gender Gap in Life Expectancy: A CrossNational Analysis, 1980-2005 // Social Science Quarterly. 2012. Vol. 93. No. 3. Pp. 820-837.

Cockerham W.C. The intersection of life expectancy and gender in a transitional state: the case of Russia // Sociology of Health \& Illness. 2012. Vol. 34. No. 6. Pp. 943-957.
Conti S., Farchi G., Masocco M., Minelli G., Toccaceli V., Vichi M. Gender differentials in life expectancy in Italy // European Journal of Epidemiology. 2003. No. 18. Pp. 107-112.

Jusrut P., Kalipeni E. An analysis of gender-based reversal in life expectancy in southern Africa // GeoJournal. 2012. No. 77. Pp. 541-554.

Kossova T. V., Kossova E. V., Sheluntcova M. Investigating the Volume and Structure Of Alcohol Consumption And Their Impact On Life Expectancy In Russian Regions // NRU Higher School of Economics. Series WP BRP "Economics/EC". 2014. No. WP BRP 82/EC/2014.

Liu Y., Arai A., Obayashi Y., Kanda K., Boostrom E., Lee R. B., Tamashiro H. Trends of gender gaps in life expectancy in Japan, 1947-2010: Associations with gender mortality ratio and a social development index // Geriatr Gerontol Int. 2013. No. 13. Pp. 792-797.

Pietilä I., Rytkönen M. 'Health is not a man's domain': lay accounts of gender difference in life-expectancy in Russia // Sociology of Health \& Illness. 2008. Vol. 30. No. 7. Pp. 1070-1085.

Triokhin A., Budilova E. V., Thomas F., Guegan JF. Worldwide Variation in LifeSpan Sexual Dimorphism and Sex-Specific Environmental Mortality Rates // Human Biology. 2004. Vol. 76. No. 4. Pp. 623-641.

Van Oyen H., Cox B., Jagger C., Cambois E., Nusselder W., Gilles C., Robine J-M. Gender gaps in life expectancy and expected years with activity limitations at age 50 in the European Union: associations with macro-level structural indicators // European Journal of Ageing. 2010. No. 7. Pp. 229-237.

Yang S., Khang Y-H., Chun H., Harper S., Lynch J. The changing gender differences in life expectancy in Korea 1970-2005 // Social Science \& Medicine. 2012. No. 75. Pp. $1280-1287$.

Статья поступила 06.12.2017

\section{Summary}

Kossova T. V., Kossova E.V., Sheluntcova M.F., National Research University Higher School of Economics, Moscow

An Analysis of the Factors Determining the Difference in life Expectancy of Men and Women in Russian Regions

The paper investigates regional differences in life expectancy at birth of women and men. We assume that gender gap in life expectancy is related to economic conditions in a region and the tendency to unhealthy lifestyles, particularly to alcohol consumption. We include into analysis mortality from external causes and mortality from respiratory diseases, since they are associated with alcohol abuse and smoking. Data source is the Federal State Statistics Service of Russia. Panel data analysis of 1990-2014 shows significant positive effect of alcohol consumption on the gender gap in life expectancy. Results confirm the importance of maintaining restrictive anti-alcohol measures in the country.

life expectancy at birth; mortality; alcohol consumption; regional differences; Russia

\section{References}

Aganbegjan A. G. 2015. Povyshenie krajne nizkoj prodolzhitel'nosti zhizni naselenija Rossii - vazhnejshaja neotlozhnaja zadacha. Jekonomicheskie strategii. T. 17, No. 5-6(130-131). Pp. 60-79. (In Russ). 
Andreev E. M. 2003. Pochemu v Rossii tak velik razryv v prodolzhitel'nosti zhizni muzhchin i zhenshhin (Opublikovano v zhurnale "Voprosy statistiki", 2001, No. 7 pod nazvaniem "Smertnost' muzhchin v Rossii"). Demoskop Weekly. No. 131-132. Available at: http://demoscope.ru/weekly/2003/0131/analit05.php. (In Russ).

Harchenko V. I., Mihajlova R. Ju., Onishhenko P. I. 2003. Pokazateli prodolzhitel'nosti zhizni naselenija Rossii v sravnenii s drugimi stranami. Problemy prognozirovanija. No. 6. Pp. 119-127. (In Russ).

Kvasha E.A., Har'kova T.L. 2011. Ozhidaemaja prodolzhitel'nost' zhizni vzroslogo naselenija v regionah Rossii v poslednee desjatiletie. Voprosy statistiki. No. 8. Pp. 26-41. (In Russ).

Shkol'nikov V.M., Andreev E. M., Makki M., Leon D. A. 2014. Rost prodolzhitel'nosti zhizni v Rossii 2000-h godov. Demograficheskoe obozrenie. T. 1. No. 2(2). Pp. 5-37. (In Russ).

Clark R., Peck M.B. 2012. Examining the Gender Gap in Life Expectancy: A CrossNational Analysis, 1980-2005. Social Science Quarterly. Vol. 93. No. 3. Pp. 820-837.

Cockerham W.C. 2012. The intersection of life expectancy and gender in a transitional state: the case of Russia. Sociology of Health \& Illness. Vol. 34. No. 6. Pp. 943-957.

Conti S., Farchi G., Masocco M., Minelli G., Toccaceli V., Vichi M. 2003. Gender differentials in life expectancy in Italy. European Journal of Epidemiology. No. 18. Pp. 107-112.

Jusrut P., Kalipeni E. 2012. An analysis of gender-based reversal in life expectancy in southern Africa. GeoJournal. No. 77. Pp. 541-554.

Kossova T. V., Kossova E. V., 2014. Sheluntcova M. Investigating the Volume and Structure Of Alcohol Consumption And Their Impact On Life Expectancy In Russian Regions. NRU Higher School of Economics. Series WP BRP "Economics/EC". No. WP BRP 82/EC/2014.

Liu Y., Arai A., Obayashi Y., Kanda K., Boostrom E., Lee R. B., Tamashiro H. 2013. Trends of gender gaps in life expectancy in Japan, 1947-2010: Associations with gender mortality ratio and a social development index. Geriatr Gerontol Int. No. 13. Pp. 792-797.

Pietilä I., Rytkönen M. 2008. 'Health is not a man's domain': lay accounts of gender difference in life-expectancy in Russia. Sociology of Health \& Illness. Vol. 30. No. 7. Pp. 1070-1085.

Triokhin A., Budilova E. V., Thomas F., Guegan JF. 2004. Worldwide Variation in Life-Span Sexual Dimorphism and Sex-Specific Environmental Mortality Rates. Human Biology. Vol. 76. No. 4. Pp. 623-641.

Van Oyen H., Cox B., Jagger C., Cambois E., Nusselder W., Gilles C., Robine J-M. 2010. Gender gaps in life expectancy and expected years with activity limitations at age 50 in the European Union: associations with macro-level structural indicators. European Journal of Ageing. No. 7. Pp. 229-237.

World Health Organization 2016. Life expectancy. Data by country. Available at: http://apps.who.int/gho/data/node.main.688?lang=en

Yang S., Khang Y-H., Chun H., Harper S., Lynch J. 2012. The changing gender differences in life expectancy in Korea 1970-2005. Social Science \& Medicine. No. 75. Pp. $1280-1287$. 